\title{
Caudal epidural block instead of general anesthesia in an adult with Duchenne muscular dystrophy
}

This article was published in the following Dove Press journal: Local and Regional Anesthesia

\author{
Shabana Z Shafy' \\ Mohammed Hakim' \\ Mauricio Arce Villalobos 1 \\ Gregory D Pearson ${ }^{2,3}$ \\ Giorgio Veneziano' \\ Joseph D Tobias ${ }^{1,4}$ \\ 'Department of Anesthesiology \\ and Pain Medicine, Nationwide \\ Children's Hospital, Columbus, $\mathrm{OH}$, \\ USA; ${ }^{2}$ Department of Plastic Surgery, \\ Nationwide Children's Hospital, \\ Columbus, OH, USA; ${ }^{3}$ Department \\ of Plastic Surgery, The Ohio State \\ University, Columbus, Ohio, USA; \\ ${ }^{4}$ Department of Anesthesiology \& Pain \\ Medicine, The Ohio State University, \\ Columbus, Ohio, USA
}

\begin{abstract}
Duchenne muscular dystrophy (DMD), first described in 1834, is an X-linked dystrophinopathy, leading to early onset skeletal muscle weakness. Life expectancy is reduced to early adulthood as a result of involvement of voluntary skeletal muscles with respiratory failure, orthopedic deformities, and associated cardiomyopathy. Given its multisystem involvement, surgical intervention may be required to address the sequelae of the disease process. We present a 36-year-old adult with DMD, who required anesthetic care during surgical debridement of an ischial pressure sore. Given his significant respiratory muscle involvement, ultrasound-guided caudal epidural anesthesia was used instead of general during the surgical procedure. The technique and its applications are discussed, with particular emphasis on the feasibility and safety of using regional anesthetic techniques in patients with DMD.
\end{abstract}

Keywords: Duchenne's muscular dystrophy, caudal epidural, regional anesthesia

\section{Introduction}

Duchenne muscular dystrophy (DMD), an X-linked disorder, is the most common form of muscular dystrophy. It results from mutations in the dystrophin gene, located on chromosome Xp21.1. ${ }^{1}$ Dystrophin is an integral protein in regulation of the integrity of sarcolemma. Mutations resulting in either dysfunction or total absence of this protein, result in interruption of the sarcolemma with progressive myofibril atrophy, necrosis, and fibrosis. ${ }^{2,3}$ DMD patients develop progressive neuromuscular weakness, skeletal deformities, and cardiopulmonary complications, with cardiac or respiratory failure being the primary cause of death during the second and third decades of life. ${ }^{4}$ Patients with DMD may present for surgical procedures to correct progressive orthopedic deformities resulting from the disease process. Given the associated respiratory and cardiac involvement, anesthetic care remains challenging. ${ }^{2,5}$ Patients with DMD are especially susceptible to the adverse effects of general anesthesia and procedural sedation. Specific concerns that may arise include difficult endotracheal intubation, prolonged neuromuscular blockade, the need for postoperative ventilation, and hyperkalemia, rhabdomyolysis, and cardiac arrhythmias resulting from prolonged exposure to volatile anesthetic agents. ${ }^{4,5}$ To avoid the aforementioned perioperative risks, regional anesthetic techniques may be considered as an alternative to general anesthesia. We present the use of caudal epidural anesthesia as an alternative to general anesthesia in a 36-year-old man with DMD who presented for debridement of an ischial pressure injury. The use of regional anesthesia in this patient population is discussed, and techniques for catheter placement reviewed.
Correspondence: Shabana Z Shafy Department of Anesthesiology \& Pain Medicine, Nationwide Children's Hospital, 700 Children's Drive Columbus, $\mathrm{OH} 43205$, USA

$\mathrm{Tel}+$ I 6147224360

Fax + 6147224203

Email shabana.shafy@

nationwidechildrens.org 


\section{Case report}

Written, informed consent was obtained from the patient for publication of this case report. Institutional Review Board (Nationwide Children's Hospital, Columbus, OH, USA) approval is not required for publication of isolated case reports. The patient was a 36-year-old, $61.1 \mathrm{~kg}$ adult, scheduled for surgical debridement of a right ischial pressure ulcer at an unspecified stage (ICD code: L89.319). His past history was positive for DMD; restrictive lung disease with chronic respiratory failure requiring Bilevel Positive Airway Pressure (BiPAP) support at night and Sipper ventilator support during the day. He also had a history of dysphagia and swallowing dysfunction with pulmonary aspiration resulting in gastric tube dependence. Echocardiography showed normal cardiac anatomy with mild left ventricular systolic dysfunction and an ejection fraction of $53 \%$. His past surgical history was significant for posterior spinal fusion and gastrostomy, during which there was no history of problems with general anesthesia other than difficult vascular access. He had no known allergies. Medication included ranitidine (150 mg twice a day), sertraline (100 mg, once a day), metoprolol tartrate ( $25 \mathrm{mg}$, twice a day), enalapril (10 mg, twice a day), sennosides-docusate (once a day), polyethylene glycol (17 g, once a day), and multivitamin supplements. Physical examination revealed a thyromental distance of more than three fingerbreadths and a Mallampati Class I airway. There was limited range of motion (flexion and extension) of the neck. A thoracolumbar surgical scar from the previous posterior spinal fusion was noted on his back, and the spinous processes from $\mathrm{T}_{2}$ to $\mathrm{L}_{5}$ could not be palpated. The remainder of the physical examination and preoperative vital signs were unremarkable. After review of the patient's current status of a difficult airway and significant restrictive lung disease requiring ventilator dependence, previous history of associated comorbid conditions, and after discussion with consulting services, it was decided to offer regional instead of general anesthesia. This patient had difficult anatomy for lumbar epidural of spinal anesthesia because of the fused spinous processes from his prior spinal fusion surgery and dense scar tissue on the back. The spinous processes from $\mathrm{T}_{2}$ to $\mathrm{L}_{5}$ were not felt and appropriate landmark palpation was not possible due to adipose tissue over the sacral area. Given the patient's previous history of posterior spinal fusion and his difficult anatomy, it was decided that the best option for neuraxial anesthesia would be caudal epidural anesthesia with ultrasound guidance. The anesthetic plan, risks, benefits, and options including caudal epidural anesthesia were discussed with the patient and informed consent obtained. On the day of surgery, the patient was held nil per os and gastric tube feeding were held for 8 hours. His usual morning doses of sertraline and ranitidine were administered through the gastric tube while the enalapril was held. He was transferred to the operating room with his BiPAP machine using his usual night-time settings (20/4 $\mathrm{cmH}_{2} \mathrm{O}$ ). He was positioned in left lateral decubitus position, standard American Society of Anesthesiologists monitors were placed, and ultrasound-guided peripheral intravenous access was achieved. Midazolam (a total of $4 \mathrm{mg}$ in divided doses) was administered intravenously for anxiolysis. After sterile preparation, superficial anesthesia of the skin and subcutaneous tissue was achieved with $1 \%$ lidocaine. Ultrasound imaging (GE 12L-RS linear transducer, GE Medical Systems Co., Jiangsu, People's Republic of China) of the sacral hiatus was performed in the transverse and longitudinal views (Figures 1 and 2). Ultrasound imaging of the sacral area also demonstrated the sacral hiatus displaced $\sim 4-5 \mathrm{~cm}$ toward the right from the midline. On the first attempt, a 3.5 inch, 17-gauge Tuohy needle (Epimed Spirol ${ }^{\circledR}$ Epidural Set, Epimed International Inc., Dallas, TX, USA) was advanced under ultrasound guidance toward and through the sacrococcygeal ligament into the caudal epidural space (Figure 3). A 19-gauge epidural catheter was advanced through the needle and into the epidural space. The Tuohy needle was removed and $10 \mathrm{~cm}$ of the catheter left in the caudal epidural space and secured in place. An initial bolus dose of $5 \mathrm{~mL}$ of $3 \%$ chloroprocaine was administered. After 5 minutes, sensory changes were noted to pin prick and temperature test in the lower extremities with no systemic complaints. An additional $10 \mathrm{~mL}$ of $3 \%$ chloroprocaine was administered and adequate surgical anesthesia was achieved over the sacral dermatomes. During the procedure, the patient received one additional bolus of $5 \mathrm{~mL}$ of $3 \%$ chloroprocaine, 15 minutes after the start of the procedure. No significant changes were noted in heart rate or blood pressure with the administration of the epidural medications. The only other intraoperative medication was intravenous acetaminophen $(1,000 \mathrm{mg})$ for postoperative analgesia. The surgical procedure, which lasted $\sim 30$ minutes, was completed with minimal blood loss and no intraoperative complications. The patient remained on nasal BiPAP until the end of the procedure. Following completion of the surgical procedure, the caudal epidural catheter was removed in the operating room. The patient's postoperative course was unremarkable. He remained as an inpatient for wound care and underwent a second brief procedure, which was performed with the administration of local anesthetic to the surgical site, 1 week after the first procedure. He was discharged home the day following the second procedure. 


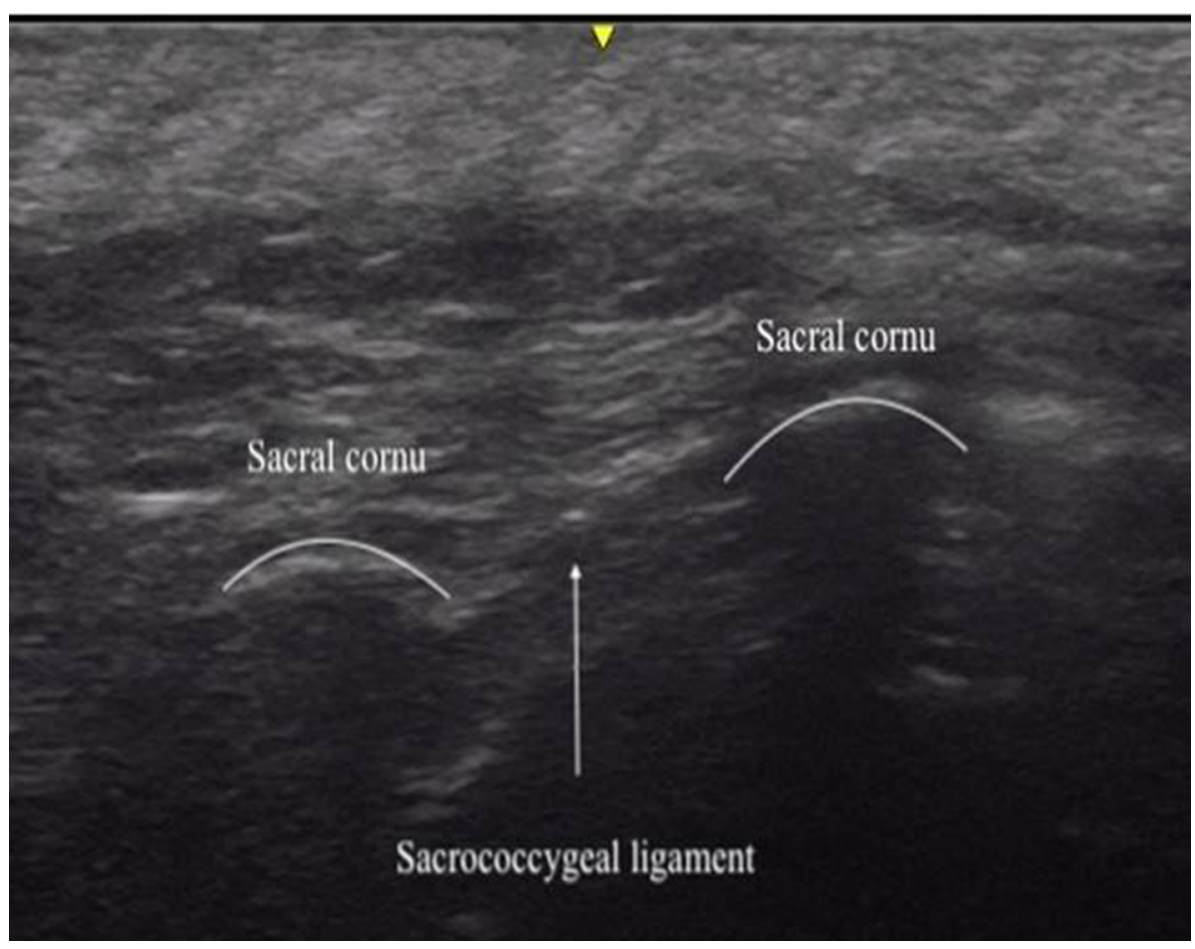

Figure I Transverse ultrasound image of the sacrum at the level of the sacrococcygeal ligament showing the ligament and the sacral cornu.

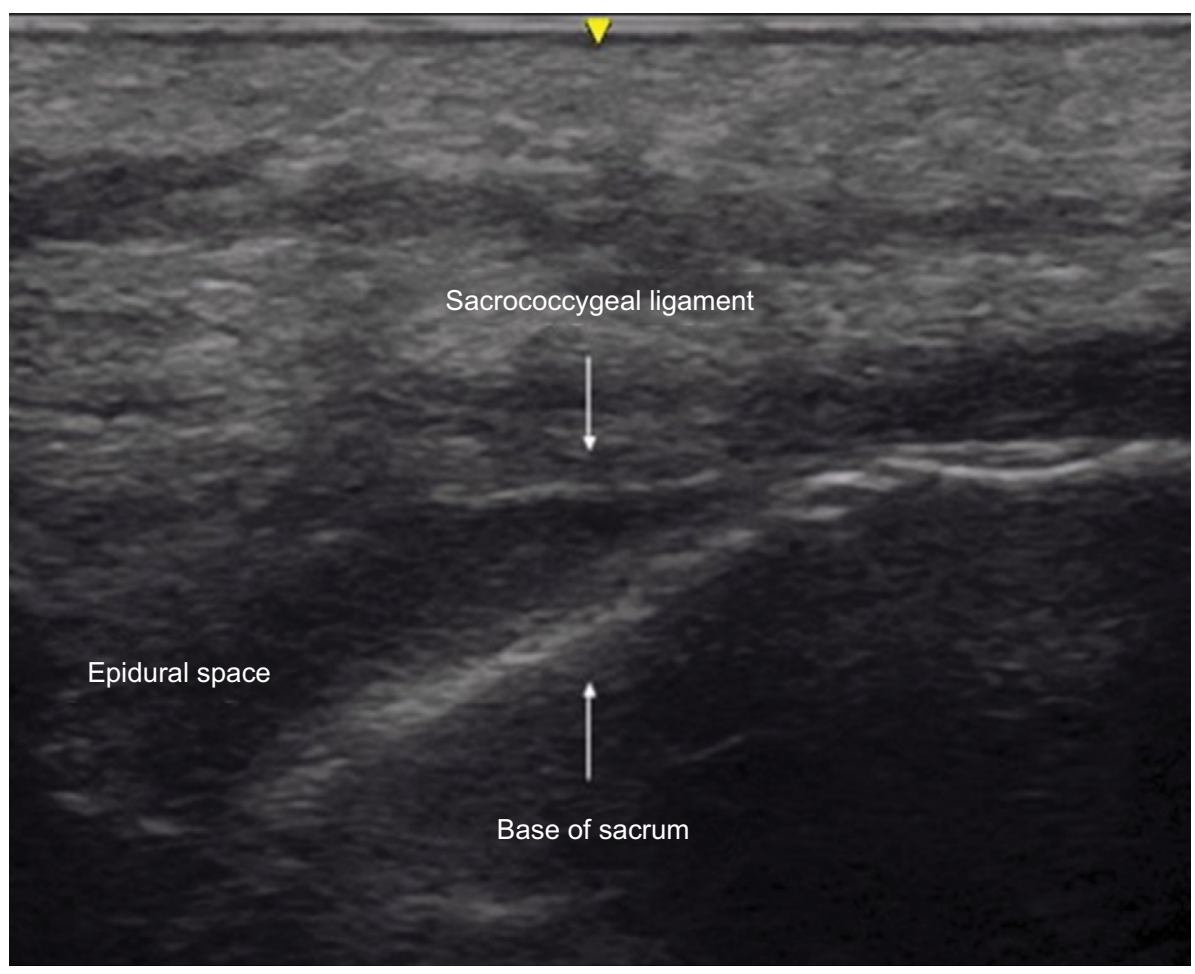

Figure 2 Longitudinal image of the sacrum showing the sacrococcygeal ligament, the base of the sacrum, and the caudal epidural space. 


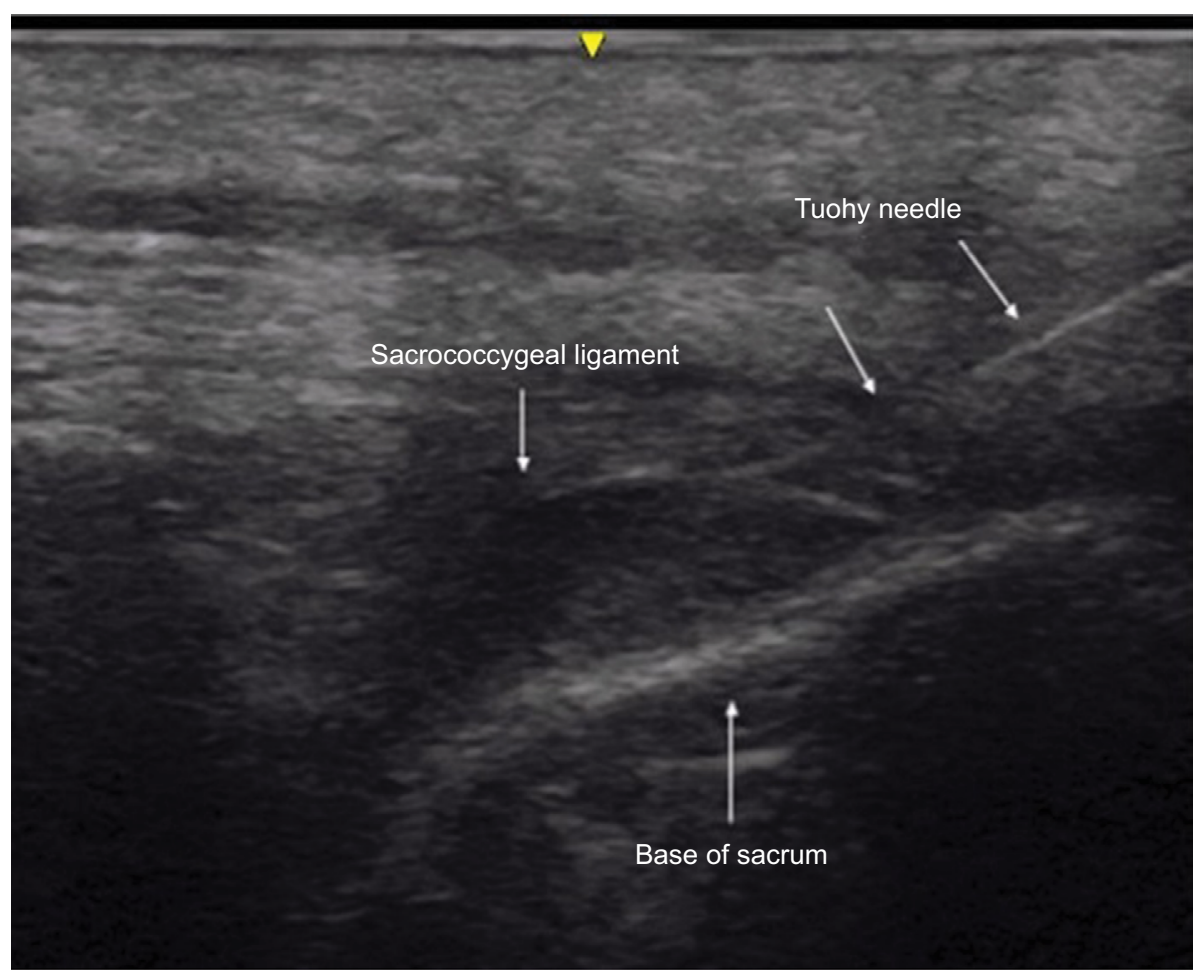

Figure 3 Longitudinal image of the sacrum showing the advancement of the Tuohy needle toward the sacrococcygeal ligament.

\section{Discussion}

Caudal epidural anesthesia, with the injection of a local anesthetic agent into the epidural space through the sacral hiatus, is commonly used to provide postoperative analgesia in pediatric patients. ${ }^{6,7}$ The technique may also be used instead of general anesthesia to avoid potential perioperative complications in patients with comorbid conditions. ${ }^{8}$ Although the lumbar approach to the epidural space is frequently chosen for surgical anesthesia in older patients, the caudal approach may be used when previous surgical procedures or anatomical deformities preclude the lumbar approach. Such was the case in our patient, as he had previously undergone posterior spinal fusion with instrumentation which limited access to the lumbar epidural space.

Needle or catheter placement for caudal epidural anesthesia may be achieved using superficial anatomical landmarks or fluoroscopy-guided or ultrasound-guided techniques. ${ }^{9-11}$ Klocke et a ${ }^{10}$ first described the use of ultrasound to achieve caudal epidural access for the administration of epidural corticosteroids. Although frequently performed in children using a blind approach with palpation of bony landmarks on the sacrum, given our patient's body habitus, his previous surgical procedure on the lumbosacral spine, and difficulties with palpation of sacral bony landmarks, we chose to use ultrasound to identify the site of needle entry and guide insertion of the needle into the caudal epidural space.
Anesthesia-related concerns in patients with DMD include potential difficulties with airway management and endotracheal intubation, restrictive pulmonary disease, cardiac muscle involvement with cardiomyopathy, and the potential for adverse effects associated with the prolonged administration of inhalational anesthetic agents. ${ }^{5,12-15}$ Given these concerns, regional anesthesia has been used as a means of avoiding general anesthesia and its potential complications in patients with DMD (Table 1). ${ }^{16-20}$ As with our patient, these anecdotal reports demonstrate the feasibility of using various regional anesthetic techniques instead of general anesthesia in this patient population.

Caudal epidural anesthesia is achieved by the injection of a local anesthetic agent into the epidural space. Potential complications associated with caudal epidural anesthesia include those related to needle placement and those from the local anesthetic agent. ${ }^{21-23}$ Complications related to needle placement include dural puncture, bleeding, infection, and trauma to neural elements or the spinal cord. Coagulation parameters including platelet count should be evaluated prior to needle placement. Given our patient's previous surgical procedure involving the lumbar spine and his anatomical challenges, we chose the caudal approach to the epidural space with ultrasound guidance to limit the potential for complications related to needle placement. Complications related to the local anesthetic agent include local anesthetic 
Table I Reports of regional instead of general in DMD patients

\begin{tabular}{|l|l|l|}
\hline Study & Patient demographics & Outcome \\
\hline Molyneux et al ${ }^{16}$ & $\begin{array}{l}\text { A 36-year-old woman with } \\
\text { DMD }\end{array}$ & $\begin{array}{l}\text { Combined spinal-epidural anesthesia for Cesarean section. Successful intraoperative care } \\
\text { with uneventful postoperative course }\end{array}$ \\
\hline Bang et al ${ }^{17}$ & A 22-year-old man with DMD & $\begin{array}{l}\text { The patient was scheduled to undergo reduction and internal fixation of a left distal femur } \\
\text { fracture. Under ultrasound guidance, separate injections were performed to provide } \\
\text { anesthesia of the femoral and lateral femoral cutaneous nerves as well as the sacral plexus. } \\
\text { The surgical procedure was performed using the regional anesthetic technique and his } \\
\text { postoperative period was uneventful }\end{array}$ \\
\hline So et al ${ }^{18}$ & $\begin{array}{l}\text { Two patients (2 and I4 years } \\
\text { of age) with presumed DMD }\end{array}$ & $\begin{array}{l}\text { Muscle biopsy to confirm the diagnosis of DMD was performed after peripheral blockade } \\
\text { (interscalene and femoral) with ultrasound guidance and nerve stimulation }\end{array}$ \\
\hline Vandepitte et al ${ }^{19}$ & $\begin{array}{l}\text { A 27-year-old male patient } \\
\text { with DMD }\end{array}$ & $\begin{array}{l}\text { Drainage of a thoracic wall hematoma was performed after intercostal nerve blockade } \\
\text { under ultrasound guidance }\end{array}$ \\
\hline Büget et al ${ }^{20}$ & $\begin{array}{l}\text { A I7-year-old male patient } \\
\text { with DMD }\end{array}$ & $\begin{array}{l}\text { Echocardiography demonstrated dilated cardiomyopathy, mitral regurgitation, and an } \\
\text { ejection fraction of 23\%. Supraclavicular block provided anesthesia for resection of a } \\
\text { rhabdomyosarcoma and left arm amputation }\end{array}$ \\
\hline
\end{tabular}

Abbreviation: DMD, Duchenne muscular dystrophy.

systemic toxicity, cardiovascular effects from sympathetic blockade, and high motor blockade with respiratory effects. Slow incremental injection is recommended especially in patients with comorbid cardiac involvement to allow for monitoring of potential hemodynamic effects (hypotension and bradycardia). Judicious fluid administration or administration of a vasoactive agent may be needed to treat hemodynamic changes. To achieve the rapid onset of epidural anesthesia and limit the potential for systemic toxicity, given its rapid systemic metabolism, we chose to use chloroprocaine. ${ }^{24} \mathrm{An}$ additional concern regarding placement of a caudal epidural catheter vs lumbar or thoracic placement is the potential risk of infection given its location in the sacral dermatomes and risk of fecal soiling and contamination. As with all placement techniques, adequate skin preparation and coverage with a bio-occlusive dressing may help limit the potential for such concerns. Furthermore, subcutaneous tunneling has been suggested as an option when caudal epidural catheters are left in place for prolonged postoperative use. ${ }^{25}$ This approach was not utilized in our patient as short-term intraoperative use of the catheter was planned.

We present the use of caudal epidural anesthesia in a patient with DMD and significant respiratory involvement to avoid the potential risks and perioperative complications associated with general anesthesia. Given previous spinal surgery with fusion and instrumentation, we chose a caudal approach to the epidural space. Ultrasound guidance was used to guide needle and catheter placement due to limited ability to identify anatomical landmarks. Our report adds additional anecdotal experience to that previously reported demonstrating the potential efficacy of using regional anesthesia instead of general anesthesia in this challenging patient population.

\section{Disclosure}

The authors report no conflicts of interest in this work.

\section{References}

1. Kunkel LM, Monaco AP, Middlesworth W, Ochs HD, Latt SA. Specific cloning of DNA fragments absent from the DNA of a male patient with an X chromosome deletion. Proc Natl Acad Sci U S A. 1985;82(14):4778-4782.

2. Hopkins PM. Anaesthesia and the sex-linked dystrophies: between a rock and a hard place. Br J Anaesth. 2010;104(4):397-400.

3. Ohlendieck K, Matsumura K, Ionasescu VV, et al. Duchenne muscular dystrophy: deficiency of dystrophin-associated proteins in the sarcolemma. Neurology. 1993;43(4):795-800.

4. Connuck DM, Sleeper LA, Colan SD, et al. Characteristics and outcomes of cardiomyopathy in children with Duchenne or Becker muscular dystrophy: a comparative study from the Pediatric Cardiomyopathy Registry. Am Heart J. 2008;155:998-1005.

5. Cripe LH, Tobias JD. Cardiac considerations in the operative management of the patient with Duchenne or Becker muscular dystrophy. Paediatr Anaesth. 2013;23(9):777-784.

6. Campbell MF. Caudal anesthesia in children. J Urol. 1933;30:2 45-250.

7. Schloss B, Martin D, Tripi J, Klingele K, Tobias JD. Caudal epidural blockade for major orthopedic hip surgery in adolescents. Saudi $J$ Anaesth. 2015;9(2):128-131.

8. Tobias JD, Hersey S. Continuous caudal anaesthesia during inguinal hernia repair in an awake, $1440 \mathrm{~g}$ infant. Pediatric Anesthesia. 1994;4(3):187-189.

9. Renfrew DL, Moore TE, Kathol MH, El-Khoury GY, Lemke JH, Walker CW. Correct placement of epidural steroid injections: fluoroscopic guidance and contrast administration. AJNR Am J Neuroradiol. 1991;12(5):1003-1007.

10. Klocke R, Jenkinson T, Glew D. Sonographically guided caudal epidural steroid injections. J Ultrasound Med. 2003;22(11):1229-1232.

11. Chen CP, Tang SF, Hsu TC, et al. Ultrasound guidance in caudal epidural needle placement. Anesthesiology. 2004;101(1):181-184.

12. Rubiano R, Chang JL, Carroll J, Sonbolian N, Larson CE. Acute rhabdomyolysis following halothane anesthesia without succinylcholine. Anesthesiology. 1987;67(5):856-857.

13. Chalkiadis GA, Branch KG. Cardiac arrest after isoflurane anaesthesia in a patient with Duchenne's muscular dystrophy. Anaesthesia. 1990;45(1): $22-25$. 
14. Nathan A, Ganesh A, Godinez RI, Nicolson SC, Greeley WJ. Hyperkalemic cardiac arrest after cardiopulmonary bypass in a child with unsuspected duchenne muscular dystrophy. Anesth Analg. 2005;100(3):672-674.

15. Hayes J, Veyckemans F, Bissonnette B. Duchenne muscular dystrophy: an old anesthesia problem revisited. Paediatr Anaesth. 2008;18(2):100-106.

16. Molyneux MK. Anaesthetic management during labour of a manifesting carrier of Duchenne muscular dystrophy. Int J Obstet Anesth. 2005;14(1):58-61.

17. Bang SU, Kim YS, Kwon WJ, Lee SM, Kim SH. Peripheral nerve blocks as the sole anesthetic technique in a patient with severe Duchenne muscular dystrophy. J Anesth. 2016;30(2):320-323.

18. So M, Sugiura T, Yoshizawa S, Sobue K. Two cases of Duchenne Muscular Dystrophy that showed different reactions to nerve stimulation during peripheral nerve block: a case report. A A Case Rep. 2017;9(2):52-53.

19. Vandepitte C, Gautier P, Bellen P, Murata H, Salviz EA, Hadzic A. Use of ultrasound-guided intercostal nerve block as a sole anaesthetic technique in a high-risk patient with Duchenne muscular dystrophy. Acta Anaesthesiol Belg. 2013;64(2):91-94.
20. Büget Mİ, Eren İ, Küçükay S, Mi B. Regional anaesthesia in a Duchenne muscular dystrophy patient for upper extremity amputation. Agri. 2014;26(4):191-195.

21. Borghi B, Casati A, Iuorio S, et al. Frequency of hypotension and bradycardia during general anesthesia, epidural anesthesia, or integrated epidural-general anesthesia for total hip replacement. J Clin Anesth. 2002;14:102-106.

22. Horlocker TT. Complications of spinal and epidural anesthesia. Anesthesiol Clin North America. 2000;18(2):461-485.

23. Tanaka K, Watanabe R, Harada T, Dan K. Extensive application of epidural anesthesia and analgesia in a university hospital: incidence of complications related to technique. Reg Anesth. 1993;18(1): 34-38.

24. Veneziano G, Iliev P, Tripi J, et al. Continuous chloroprocaine infusion for thoracic and caudal epidurals as a postoperative analgesia modality in neonates, infants, and children. Paediatr Anaesth. 2016;26(1):84-91.

25. Bubeck J, Boos K, Krause H, Thies KC. Subcutaneous tunneling of caudal catheters reduces the rate of bacterial colonization to that of lumbar epidural catheters. Anesth Analg. 2004;99(3):689-693.
Local and Regional Anesthesia

\section{Publish your work in this journal}

Local and Regional Anesthesia is an international, peer-reviewed, open access journal publishing on the development, pharmacology, delivery and targeting and clinical use of local and regional anesthetics and analgesics. The journal is included in PubMed, and welcomes submitted papers covering original research, basic science, clinical studies,

\section{Dovepress}

reviews and evaluations, guidelines, expert opinion and commentary, case reports and extended reports. The manuscript management system is completely online and includes a very quick and fair peer-review system, which is all easy to use. Visit http://www.dovepress.com/ testimonials.php to read real quotes from published authors. 